\title{
Flow Injection Analysis with On-Line Preconcentration of Trace Selenium
}

\author{
Eiji Aoyama*, Keiko Akamatsu*, Terumichi Nakagawa* and Hisashi Tanaka** \\ *Faculty of Pharmaceutical Sciences, Kyoto University, Sakyo, Kyoto 606, Japan \\ **Kyoto Pharmaceutical University, Yamashina, Kyoto 607, Japan
}

\begin{abstract}
A flow injection analysis system has been developed for the determination of very low concentrations $(<1 \mathrm{ng} / \mathrm{ml})$ of selenium(IV). The system involves a micro column packed with a resin loaded with Bismuthiol-II sulfonate (Bis-II S) for the on-line preconcentration of trace selenium(IV) and a manifold for the quantification of selenium based on the Secatalyzed reduction of 3-(4,5-dimethyl-2-thiazolyl)-2,5-diphenyl-2 $H$ tetrazolium bromide (MTT). Selenium was selectively collected as selenotrisulfide (-S-Se-S-) on the resin by reaction with Bis-II S, and eluted with a small volume of penicillamine solution which withdraws the selenium from the resin. Selenium thus eluted as penicillamine selenotrisulfide was introduced to the flow injection analyzer, where penicillamine selenotrisulfide catalyzes the reduction of MTT to formazan by dithiothreitol. The interference from copper ion was eliminated by the adsorption of $\mathrm{Cu}$ on the resin as a bathocuproine disulfonate chelate. Reliability of the present method was confirmed from the determination of selenium contents in a biological standard sample.
\end{abstract}

Keywords Selenium, preconcentration, flow injection analysis, catalytic analysis

Selenium has been recognized as being an element which has both essential ${ }^{1}$ and toxic ${ }^{2}$ activities in humans. Both its deficiency and excess uptake can cause serious disorders. Recent reports suggest the preventive role of selenium in the etiology of cancer., ${ }^{3,4}$ These biological, clinical and hygienic researches demand the determination of selenium in biological and environmental samples.

Among the methods developed for this purpose, fluorometry ${ }^{5}$, graphite furnace atomic absorption spectrometry (GF-AAS) ${ }^{6}$ and atomic absorption spectrometry with hydride generation (HG-AAS) ${ }^{7,8}$ are widely used. Fluorometry based on the formation of piazselenol by reaction of selenite with 2,3-diaminonaphthalene (DAN), though it is highly sensitive and most commonly used, needs complicated procedures such as the extraction of the fluorophore. Recent papers reported that further purification of the fluorophore by HPLC or backextraction is necessary for the determination of selenium in biological materials. ${ }^{9,10}$ GF-AAS method is sensitive and easy to apply to the biological samples, but suffers from severe spectral interference caused by iron and phosphate salts. ${ }^{11-13}$ Though HG-AAS can determine very low concentrations of selenium, it needs a large volume of sample. ${ }^{8}$

Hawkes reported a catalytic assay method of selenium based on the formation of formazan dye by Se-catalyzed reduction of Tetranitro Blue Tetrazolium by dithiothreitol. ${ }^{14}$ However, since the formazan formed is seriously adsorbed to glass and plastic materials, this reaction can not be incorporated into a flow analysis system. Thus, we selected 3-(4,5-dimethyl-2-thiazolyl)2,5-diphenyl- $H$ tetrazolium bromide (MTT) which forms a water-soluble formazan dye and applied the reaction to the FIA. ${ }^{15}$ The developed method can detect $0.63 \mathrm{pmol}$ of selenium(IV). However, selenium concentration in some biological samples such as tissue and urine and in some environmental samples such as river water and seawater is lower than the detection limit. Further, when only small amounts of samples such as tissues from mice and rats are available, selenium concentration is too dilute to be applied to the FIA method. Thus, the selective preconcentration by using the anion exchange resin loaded with Bismuthiol-II sulfonate $^{16}$ (Fig. 1) has been incorporated into the FIA method.

The present paper deals with the development of the FIA system combined with the on-line preconcentration<smiles>[R]OS(=O)(=O)c1ccc(-n2nc(S)sc2=S)cc1</smiles>

Fig. 1 Potassium Bismuthiol-II sulfonate (Bis-II S). 
of trace levels of selenium. The optimization of the conditions for the preconcentration and the elimination of interference from copper ion are also described.

\section{Experimental}

\section{Reagents}

Amberlite CG-400 was used after washing with $1 \mathrm{M}$ $\mathrm{NaOH}, 1 \mathrm{M} \mathrm{HCl}$ and water. Bismuthiol-II sulfonate potassium salt ${ }^{16}$ synthesized from 4-hydrozinobenzenesulfonic acid and carbon disulfide was kindly supplied by Dr. Kazuo Itoh (Environmental Pollution Research Institute, Nagoya, Japan). 3-(4,5-Dimethyl-2-thiazolyl)-2,5-diphenyl-2 $H$ tetrazolium bromide (MTT), disodium bathocuproine disulfonate and disodium EDTA were purchased from Dojin Laboratory (Kumamoto, Japan). Triton X-405, dithiothreitol (DTT) and a 35\% aqueous solution of formaldehyde were purchased from Wako Pure Chemical Industries Ltd. (Osaka, Japan). All other reagents were of analytical grade. A standard sample of Lobster (TORT-1) was supplied by the National Research Council (NRC, Canada). DTT solution (R1 in Fig. 3) was prepared daily by dissolving $0.22 \mathrm{~g}$ of DTT in a $100 \mathrm{ml}$ of an aqueous solution containing $0.82 \mathrm{mM}$ of $\mathrm{FeCl}_{3}$ and disodium EDTA. MTT solution (R2 in Fig. 3) was prepared by dissolving $14.5 \mathrm{mg}$ MTT in $100 \mathrm{ml}$ of a $3.3 \%$ Triton X-405 solution containing $0.45 \%$ of formaldehyde. A $0.6 \mathrm{M}$ phosphate buffer was prepared by the titration of a $0.6 \mathrm{M} \mathrm{NaH}_{2} \mathrm{PO}_{4}$ solution with a $5 \mathrm{M} \mathrm{NaOH}$ solution.

\section{Preparation of micro column packed with resin loaded with Bis-II S}

Bis-II S resin was prepared according to the previous method ${ }^{16,17}$ with a slight modification: $0.5 \mathrm{~g}$ of Amberlite CG-400 was added to a $100 \mathrm{ml}$ of aqueous solution of $2 \mathrm{mM}$ Bis-II S, and the mixture was shaken for $30 \mathrm{~min}$ at

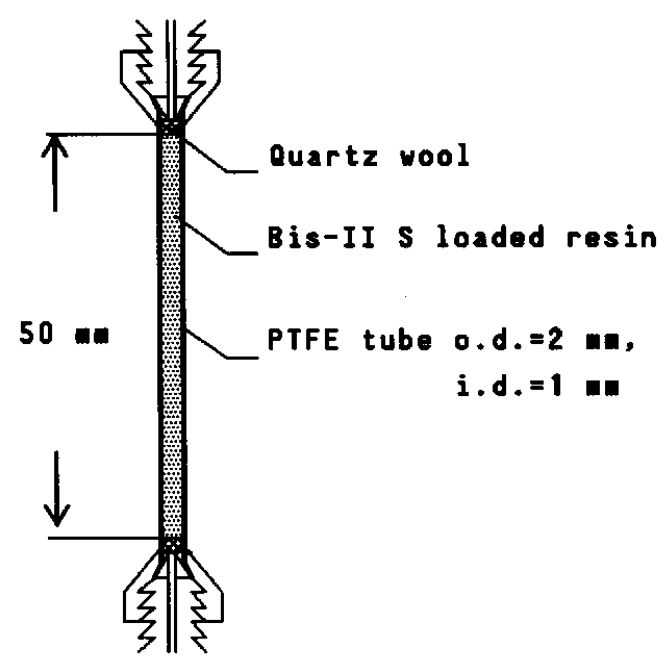

Fig. 2 Micro column packed with the Bis-II S resin. $30^{\circ} \mathrm{C}$. All Bis-II S in the solution was immobilized to give $0.4 \mathrm{mmol}$ reagent $/ \mathrm{g}$ resin. The resin was filtered, washed with methanol and water, vacuum-dried and stored in a refrigerator. A small polytetrafluoroethylene (PTFE) tube $(50 \mathrm{~mm} \times 1 \mathrm{~mm}$ i.d.) was filled with $22 \mathrm{mg}$ of the Bis-II S resin suspended in water (Fig. 2). The micro column thus prepared was dried and washed with $0.2 \mathrm{M}$ penicillamine solution and $0.1 \mathrm{M} \mathrm{HCl}$ prior to use.

\section{Flow system}

An SNK SSP-DM3M pump, an SNK SSP-DM2M pump (Sanuki Kogyo Co., Japan), an ATTO SJ1220 pump, a Shimadzu SPD-6AV spectrophotometric detector and an SNK Model FIA-305H sample injector were employed in order to set up the flow system. A PTFE tube of $0.5 \mathrm{~mm}$ i.d. was used as the mixing coil and the connecting line. The recommended flow manifold is shown in Fig. 3. The micro column packed with BisII S resin was connected to the FIA system via a 6-way valve which selects flow line A or B. The sample solution (selenium(IV) in $0.1 \mathrm{M} \mathrm{HCl}$ ) was introduced from injector 1 with a carrier of $0.1 \mathrm{M} \mathrm{HCl}$ at a flow rate of $0.1 \mathrm{ml} / \mathrm{min}$. The eluent solution containing $0.1 \mathrm{M}$ penicillamine and $15 \mathrm{mM}$ bathocuproine disulfonate was introduced from injector 2 with a carrier of $0.6 \mathrm{M}$ phosphate buffer solution ( $\mathrm{pH} 7$ ) at a flow rate of $0.2 \mathrm{ml}$ / min. Selenium eluted from the column as penicillamine selenotrisulfide was mixed with a $0.1 \mathrm{ml} / \mathrm{min}$ flow of 7.3 mM DTT solution (R1). The mixing was effected in a reaction coil $\mathrm{Cl}(4 \mathrm{~m})$. Before the second reaction coil C2 $(6 \mathrm{~m})$, the carrier stream further merged with a $0.35 \mathrm{mM}$ MTT solution (R2) at a flow rate of $0.1 \mathrm{ml} / \mathrm{min}$. The concentration of selenium was determined from the

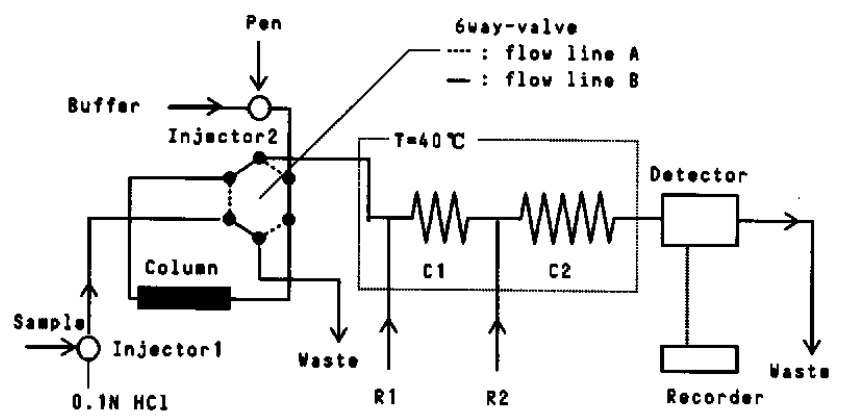

Fig. 3 FIA system with on-line preconcentration of Se(IV). Column, Bis-II S resin $(0.4 \mathrm{mmol} / \mathrm{g})$ column $(1 \mathrm{~mm}$ i.d. $X$ $50 \mathrm{~mm}$ ); Pen, $0.1 \mathrm{M}$ penicillamine in $0.6 \mathrm{M}$ phosphate buffer (pH 7) containing $7.5 \mathrm{mM}$ bathocuproine disulfonate; buffer: $0.1 \mathrm{M}$ phosphate buffer (pH 7.0), flow rate $=0.2 \mathrm{ml} / \mathrm{min}$; $0.1 \mathrm{M} \mathrm{HCl}$, flow rate $=0.28 \mathrm{ml} / \mathrm{min} ; \mathrm{R} 1: 7.3 \mathrm{mM} \mathrm{DTT}$, $0.82 \mathrm{mM} \mathrm{FeCl}_{3}, 0.82 \mathrm{mM}$ EDTA, flow rate $=0.1 \mathrm{ml} / \mathrm{min}$; R2: $0.35 \mathrm{mM}$ MTT, $3.3 \%$ Triton X-405, $0.45 \%$ formaldehyde, flow rate $=0.1 \mathrm{ml} / \mathrm{min}$; detection, absorbance at $565 \mathrm{~nm} ; \mathrm{Cl}$, Teflon tube coil $0.5 \mathrm{~mm}$ i.d. $\times 4 \mathrm{~m}$; $\mathrm{C} 2$, Teflon tube coil $0.5 \mathrm{~mm}$ i.d. $\times 6 \mathrm{~m}$; injector 1 , for the sample introduction; injector 2, for the eluent introduction. 
peak area of the formazan formed from MTT with absorption at $565 \mathrm{~nm}$. Data were recorded and processed on a Shimadzu Chromatopak C-R6A.

\section{Recommended procedure}

The flow line A of the 6-way valve (Fig. 3) was selected to connect the Bis-II S column with the injector 1. A $0.4 \mathrm{ml}$ portion of $0.2 \mathrm{M}$ penicillamine aqueous solution was injected from injector 1 to wash the column after the equilibration of the column with $0.1 \mathrm{M} \mathrm{HCl}$, and a $1 \mathrm{ml}$ portion of sample solution $(0.1 \mathrm{M} \mathrm{HCl}$ containing selenium(IV)) was injected from injector 1 . Then, the flow line was changed to $B$ in order to introduce the effluent from the column to the FIA, and the recording of the detector response was started. After the base line was stabilized, a $0.05 \mathrm{ml}$ portion of $0.6 \mathrm{M}$ phosphate buffer solution ( $\mathrm{pH} 7$ ) containing $0.1 \mathrm{M}$ penicillamine and $7.5 \mathrm{mM}$ bathocuproine disulfonate was injected from injector 2 for the elution of selenium from the column.

\section{Determination of selenium in standard sample}

About $100 \mathrm{mg}$ of standard sample of Lobster (TORT-1) in a dried powder state was accurately weighed and digested with $1.5 \mathrm{ml}$ of a mixture of $60 \%$ nitric acid and $60 \%$ perchloric acid $(10 / 5, \mathrm{v} / \mathrm{v})$ in a tightly stoppered stainless steel mini autoclave with a PTFE inner vessel. The digestion was carried out by heating the mixture at about $130^{\circ} \mathrm{C}$ for $150 \mathrm{~min}$. Then, the mixture was transferred to a small conical beaker and heated at 130 $150^{\circ} \mathrm{C}$ to evaporate excess reagent and gas until white fumes of the perchloric acid appeared. Hydrochloric acid $(60 \%, 0.5 \mathrm{ml})$ was added to the digested solution; the mixture was heated at $95^{\circ} \mathrm{C}$ for $40 \mathrm{~min}$ in a tightly capped vial to reduce selenium(VI) to selenium(IV). Water was added to the mixture to make the total volume $10 \mathrm{ml}$. By these procedures, all the selenium in the samples was converted to selenium(IV). The digested sample was diluted with water by 10 times, and $1 \mathrm{ml}$ of the diluted sample was analyzed in accord with the recommended procedure.

\section{Results and Discussion}

\section{Collection of selenium(IV) on the Bis-II S resin column}

Bismuthiol-II sulfonate has the structure shown in Fig. 1. It is bound to the anion exchange resin by the ionic and physical interactions. ${ }^{16}$ Selenium(IV) was collected as selenotrisulfide (-S-Se-S-), formed by reaction with BisII S. The adsorption of selenium(IV) to the resin was effected at $\mathrm{pH}$ below $2,{ }^{17}$ whereas the metal ions except for copper ion were not adsorbed on the resin. Therefore, the sample solution was made acidic with $0.1 \mathrm{M}$ $\mathrm{HCl}$. The Se-binding capacity of the micro column packed with Bis-II S resin was tested as shown in Fig. 4; $0.1 \mathrm{M} \mathrm{HCl}$ solution containing $4 \mu \mathrm{g} / \mathrm{ml}$ or $0.5 \mu \mathrm{g} / \mathrm{ml}$ of selenium(IV) was passed through the column at a flow rate of $0.28 \mathrm{ml} / \mathrm{min}$. The effluent from the column was

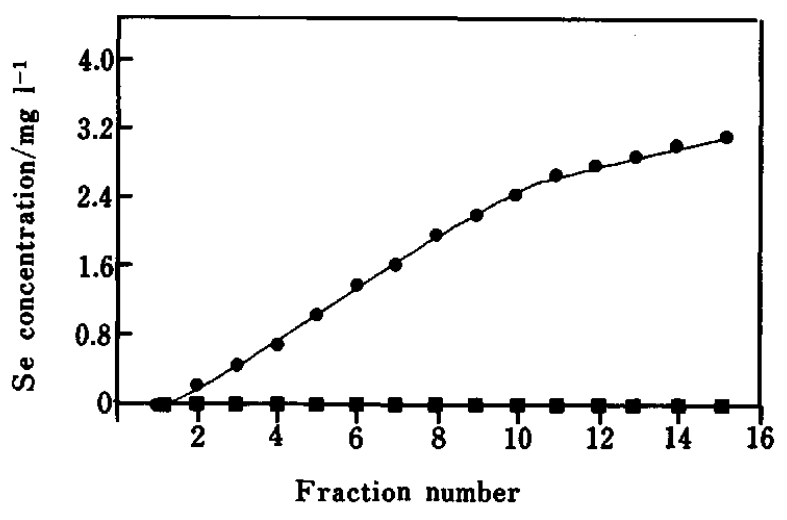

Fig. 4 Break through curve of the micro column. Fraction size, $1.4 \mathrm{ml}$; column size, $1 \mathrm{~mm}$ i.d. $\times 50 \mathrm{~mm}$; Bis-II $\mathrm{S}$ resin, $22 \mathrm{mg}$ of Amberlite CG-400 loaded with $0.4 \mathrm{mmol} / \mathrm{g}$ resin of Bis-II S; sample solution: $0.1 \mathrm{M} \mathrm{HCl}$ containing $0.5 \mu \mathrm{g} / \mathrm{ml}$ (E) or $4 \mu \mathrm{g} / \mathrm{ml}$ (O) of selenium(IV), flow rate $=0.28 \mathrm{ml} / \mathrm{min}$; temperature, ambient.

fractionated every $5 \mathrm{~min}$, and selenium contents in each fraction was determined by the reported FIA. ${ }^{15}$ When $4 \mu \mathrm{g} / \mathrm{ml}$ selenium(IV) solution (O) was used, small leakage of selenium from the column was found even in the first fraction, but no leakage was found in all the fractions from $0.5 \mu \mathrm{g} / \mathrm{ml}$ selenium(IV) solution ( $\square$ ). This shows that the micro column perfectly collects $10.5 \mu \mathrm{g}$ of selenium(IV), and the capacity is sufficient for the preconcentration of trace levels of selenium. To study the effect of flow rate on the efficiency of collection of selenium, $1 \mathrm{ml}$ of $20 \mathrm{ng} / \mathrm{ml}$ selenium(IV) in $0.1 \mathrm{M} \mathrm{HCl}$ was passed through the column at various flow rates above $0.28 \mathrm{ml} / \mathrm{min}$, and the concentration of selenium remaining in the effluent was determined. Thus, 100 , 89,81 and $75 \%$ of selenium was collected on the column at the flow rates of $0.28,0.42,0.56$ and $0.7 \mathrm{ml} / \mathrm{min}$, respectively. Thus, $0.28 \mathrm{ml} / \mathrm{min}$ was selected as the optimum flow rate.

\section{Elution of selenium from the column}

Selenium forms selenotrisulfide on the surface of the resin. The recovery of selenium from the resin can be effected by the elution with a strong acid or penicillamine solution. ${ }^{17}$ By elution with strong acid, selenium is eliminated from the resin together with Bis-II S, while only selenium is recovered when eluted with penicillamine. Cysteine solution can also recover selenium from the resin by thiol exchange reaction. ${ }^{17}$ However, because penicillamine selenotrisulfide was more stable than cysteine selenotrisulfide ${ }^{18,19}$, penicillamine solution was chosen as the eluent. Since the present FIA method has the same sensitivity for penicillamine selenotrisulfide with that for selenite, penicillamine selenotrisulfide eluted from the preconcentration column can be directly applied to FIA system with no pretreatment.

In order to investigate the effect of penicillamine concentration on the recovery of selenium, $20 \mathrm{ng}$ of selenium adsorbed on the column was eluted by injecting 


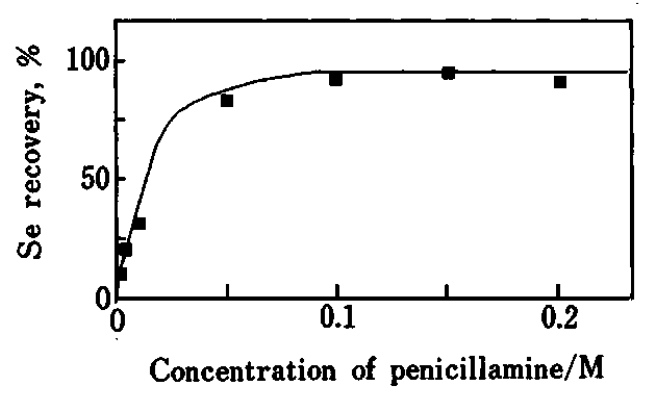

Fig. 5 Effect of penicillamine concentration on the elution of selenium collected on the Bis-II $\mathrm{S}$ resin column. Column size, $1 \mathrm{~mm}$ i.d. $\times 50 \mathrm{~mm}$; Bis-II S resin, $22 \mathrm{mg}$ of Amberlite CG-400 loaded with $0.4 \mathrm{mmol} / \mathrm{g}$ resin of Bis-II S; sample, $1.0 \mathrm{ml}$ of $0.1 \mathrm{M} \mathrm{HCl}$ containing $20 \mathrm{ng} / \mathrm{ml}$ of $\mathrm{Se}(\mathrm{IV})$; eluent, $0.05 \mathrm{ml}$ of penicillamine in $0.6 \mathrm{M}$ phosphate buffer solution (pH 7).

$0.05 \mathrm{ml}$ of various concentrations of penicillamine solution with a carrier of $0.6 \mathrm{M}$ phosphate buffer solution (pH 7) at a flow rate of $0.2 \mathrm{ml} / \mathrm{min}$. After the injection of penicillamine solution, the first $5 \mathrm{ml}$ of the effluent was fractionated. Selenium contents in the fraction were determined by the FIA method, and the recovery ratios against theoretical value were obtained as given in Fig. 5. The recovery of selenium increased with increasing concentration of penicillamine, and showed a plateau at above $0.1 \mathrm{M}$. When $0.05 \mathrm{ml}$ of $0.1 \mathrm{M}$ penicillamine was injected, $90 \%$ of selenium was recovered. Though the recovery increased to $97 \%$ with increase in the volume of $0.2 \mathrm{M}$ penicillamine solution to $0.1 \mathrm{ml}$, the concentration of selenium in the eluate was inevitably diluted. Thus, the elution with $0.05 \mathrm{ml}$ of $0.1 \mathrm{M}$ penicillamine solution was found to be optimal. Under this condition, $10 \%$ of collected selenium remained on the resin. Therefore, the column should be washed with $0.4 \mathrm{ml}$ of $0.2 \mathrm{M}$ penicillamine solution for the regeneration.

\section{Flow system}

Figure 3 illustrates the FIA system which was set up to satisfy the optimum conditions for both the preconcentration and the determination of selenium. Because selenium should be collected from an acidic solution and quantified in a neutral condition, the Bis-II S resin column was connected with the FIA system via the 6-way valve to select the two different media: $0.1 \mathrm{M} \mathrm{HCl}$ for the preconcentration and the phosphate buffer solution $(\mathrm{pH} 7)$ for the FIA. The sample solution introduced from the injector 1 enters the Bis-II S column via the flow line $\mathrm{A}$, and selenium in the sample was collected on the resin. Then, the medium was changed from $0.1 \mathrm{M} \mathrm{HCl}$ to phosphate buffer solution ( $\mathrm{pH} 7$ ), and the penicillamine solution was introduced from injector 2 to the column through flow line B. Selenium adsorbed on the resin was eluted as penicillamine selenotrisulfide, which was mixed with the streams of R1 and R2 solutions. Formazan, formed by the Se-catalyzed

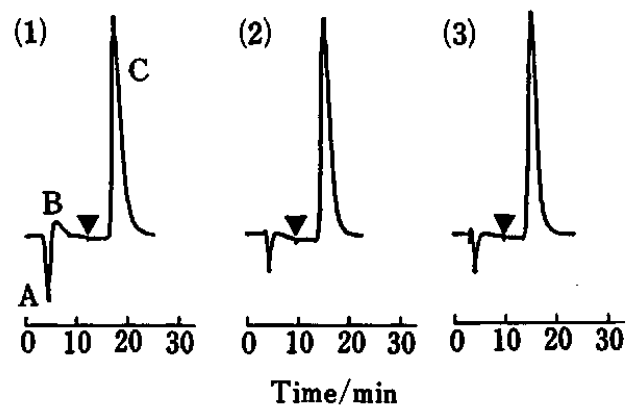

Fig. 6 Effect of carrier buffer on the FIA chart. Carrier: $0.2 \mathrm{M}$ (1), $0.4 \mathrm{M}$ (2), $0.6 \mathrm{M}$ (3) phosphate buffer ( $\mathrm{pH} 7$ ); sample, $1 \mathrm{ml}$ of $20 \mathrm{ng} / \mathrm{ml} \mathrm{Se(IV)} \mathrm{in} 0.1 \mathrm{M} \mathrm{HCl}$. A, B: negative and positive system peaks; $C$ : peak from the eluted selenium; $\nabla$ : injection of $0.2 \mathrm{M}$ penicillamine solution.

reduction of MTT in R1 by DTT in R2, was monitored by the absorbance at $565 \mathrm{~nm}$. The selenium contents were determined from the peak area of the formazan. Because penicillamine itself has also reductive activity against MTT, formazan of MTT was formed even in the absence of selenium, when penicillamine was injected. Thus, the net peak area for selenium could be obtained by subtracting the blank peak area due to penicillamine from the apparent peak area.

As shown in Fig. 6(1), a negative system peak (A) and a positive system peak (B) were obtained when the solution passing through the column was changed. These system peaks should be lowered in order to shorten the analysis time. The increase in the concentration of phosphate buffer was effective to reduce the system peaks, as demonstrated in Fig. 6.

When $1 \mathrm{ml}$ of sample solution was treated by the micro column, selenium was concentrated by 18 fold, and $0.1 \mathrm{ng} / \mathrm{ml}$ standard selenium(IV) solution could be detected. The detection limit could be lowered with increase in the volume of the sample. The calibration plots obtained from $5 \mathrm{ml} \mathrm{of} 0.1$ to $2.0 \mathrm{ng} / \mathrm{ml}$ selenium(IV) standard solutions showed a linear relationship with a correlation coefficient of 0.998 .

\section{Interferences}

As reported in the preceding paper ${ }^{15}$, the catalytic FIA method was interfered with the cooperative reduction of MTT by copper(II) ion. Because copper(II) ion is also adsorbed on the Bis-II S resin and eluted by penicillamine ${ }^{17}$, the elimination of copper ion is required. To investigate the interference from copper, a standard solution containing $20 \mathrm{ng} / \mathrm{ml}$ selenium(IV) and $2 \mu \mathrm{g} / \mathrm{ml}$ $\mathrm{Cu}$ (II) was analyzed in the flow system. The result showed a serious positive error ( 10.3 times higher). In order to eliminate the interference from copper, bathocuproine disulfonate which forms a stable and hydrophobic chelate with copper ion was added to the penicillamine solution. Though the bathocuproine itself was not adsorbed on the resin in this condition, its 
Table 1 Selenium contents $(\mu \mathrm{g} / \mathrm{g})$ in NRC-TORT-1 Lobster

\begin{tabular}{ll}
\hline Present method $^{\mathrm{a}}$ & $6.75 \pm 0.26(n=3)$ \\
FIA without preconcentration & $6.47 \pm 0.19(n=4)$ \\
Certified value & $6.88 \pm 0.47(n=3)$ \\
HG-AAS $^{\mathrm{b}}$ & $6.50 \pm 0.10(n=3)$ \\
DAN fluorometry $_{\quad \text { with Te-coprecipitation }}^{\mathrm{b}}$ & \\
Fluorometric HPLC $^{\mathrm{c}}$ & $6.25 \pm 0.55(n=3)$ \\
\hline
\end{tabular}

a. Diluted digested sample solution was employed.

b. See ref. 20 .

c. See ref. 21.

copper chelate was effectively adsorbed. Therefore, while selenium was eluted as penicillamine selenotrisulfide, copper remained on the resin as bathocuproine disulfonate chelate. The color of the resin changed from yellow to orange with increase in the adsorption of $\mathrm{Cu}$-bathocuproine disulfonate chelate. Thus, selenium in $0.1 \mathrm{M} \mathrm{HCl}$ containing $2 \mu \mathrm{g} / \mathrm{ml} \mathrm{Cu}$ (II) could be determined with the recovery of $97 \%$. The chelate was decomposed by switching the carrier from phosphate buffer ( $\mathrm{pH} 7$ ) to $0.1 \mathrm{M} \mathrm{HCl}$, and copper on the resin could be eluted with $0.2 \mathrm{M}$ penicillamine solution.

\section{Determination of selenium in standard sample}

To demonstrate the applicability of the present method to the biological samples, selenium content in a standard sample of lobster was analyzed for selenium. The recovery of selenium which was added to the standard sample at a concentration of $5 \mu \mathrm{g} / \mathrm{g}$ was $95 \%$, indicating no significant interference. For comparison, the digested sample without dilution was also analyzed by the four different methods; FIA without preconcentration $^{15}$, HG-AAS ${ }^{20}$, DAN-fluorometry ${ }^{20}$ and fluorometric HPLC which we developed. ${ }^{21}$ The results are shown in Table 1 with the certified value reported by NRC. Student's paired $t$-tests $(p<5 \%)$ indicate that there were no significant differences among the certified value and the assay values obtained by these methods. The present method could precisely determine selenium content in the diluted sample solution, though it could not be assayed without preconcentration.

\section{References}

1. K. Schwartz and C. M. Foltz, J. Am. Chem. Soc., 79, 3292 (1957).

2. G. Yang, S. Wang, R. Zhou and S. Sun, Am. J. Clin. Nutr., 37, 872 (1983).

3. G. A. Greeder and J. A. Milner, Science, 209, 825 (1980).

4. N. P. Das, C. W. Ma and Y. M. Salman, Biol. Tr. Elem. Res., 10, 215 (1986).

5. K. Hiraki, O. Yoshii, H. Hirayama, Y. Nishikawa and T. Shigematsu, Bunseki Kagaku, 22, 712 (1973).

6. K. Saeed, Y. Thomassen and F. J. Langmyhr, Anal. Chim. Acta, 110, 285 (1979).

7. M. Yamamoto, M. Yasuda and Y. Yasumoto, Anal. Chem., 57, 1382 (1985).

8. C. C. Y. Chan, Anal. Chem., 57, 1482 (1985).

9. Y. Shibata, M. Morita and K. Fuwa, Anal. Chem., 56, 1527 (1984).

10. Y. Tamari, S. Ohmori and K. Hiraki, Clin.Chem., 32, 1464 (1986).

11. K. Saeed and Y. Thomassen, Anal. Chim. Acta, 130, 281 (1981).

12. P. L. H. Jowett and M. I. Banton, Anal. Lett., 19, 1243 (1986).

13. K. S. Subramanian, Prog. Anal. Spectrosc., 9, 237 (1986).

14. W. C. Hawkes, Anal. Chim. Acta, 183, 197 (1986).

15. E. Aoyama, N. Kobayashi, M. Shibata, T. Nakagawa and H. Tanaka, Anal. Sci., 7, 103 (1991).

16. M. Nakayama, T. Tanaka, M. Tanaka, M. Chikuma, K. Itoh, H. Sakurai, H. Tanaka and T. Nakagawa, Talanta, 34, 435 (1987).

17. M. Nakayama, K. Itoh, M. Chikuma, H. Sakurai and H. Tanaka, Talanta, 31, 269 (1984).

18. T. Nakagawa, Y. Hasegawa, Y. Yamaguchi, M. Chikuma, H. Sakurai, M. Nakayama and H. Tanaka, Biochem. Biophys. Res. Comm., 135, 183 (1986).

19. T. Nakagawa, E. Aoyama, N. Kobayashi, H. Tanaka, M. Chikuma, H. Sakurai and M. Nakayama, Biochem. Biophys. Res. Comm., 150, 1149 (1988).

20. K. Itoh, M. Chikuma and H. Tanaka, Fresenius' Z. Anal. Chem., 330, 600 (1988).

21. T. Nakagawa, E. Aoyama, N. Hasegawa, N. Kobayashi and H. Tanaka, Anal. Chem., 61, 233 (1989).

(Received March 2, 1991)

(Accepted May 13, 1991) 